\title{
HYPERTROPHIC OR KELOID SCARS?
}

\author{
D. A. McGROUTHER \\ London
}

\begin{abstract}
SUMMARY
Further attempts to achieve a clinical distinction between hypertrophic and keloid scars seem pointless. Research in recent years has shifted from the extracellular components towards the cells themselves. Much more work needs to be done to characterise the activities of the various cell lines and the mechanisms of their control. A key question is whether the cells are due to a different subpopulation of fibroblasts or whether they are normal wound-healing cells acting under some chemical or physical influence. Ultimately, most hypertrophic and keloid scars become flat and pale, although the time sequence is very variable and there is little understanding of the process of scar maturation. Meanwhile, the problem remains as a significant cause of human suffering deserving further investment of time and resources.
\end{abstract}

The clinical controversy as to whether hypertrophic scars and keloids are different entities or merely the opposite ends of a spectrum of wound-healing behaviour has done little to advance our understanding of the process. The name keloid applied to a raised scar is derived from the terms 'cancroid', 'cheloide' or 'keloide', used by Alibert, ${ }^{1-3}$ and the history of management of these conditions has been extensively reviewed by Linares et $\mathrm{al} .{ }^{4}$ It seems that one of the sources of our current therapeutic confusion has been the attempt to place scars with different clinical appearances into different pathological categories.

The current state of debate can be assessed from the correspondence column of the journal Plastic and Reconstructive Surgery, following a comprehensive review article on the subject by Rockwell et al. $;^{5}$ they suggested that the distinction between hypertrophic scars and keloid was not important. Brody ${ }^{6}$ disagreed and presented a table of distinguishing features. A prominent point in this table was that a keloid scar 'overgrows its boundaries' but significantly the illustration of Brody's table suggests a no-man's-land labelled 'scars that lie in between [hypertrophic and keloid] and have characteristics of both'. A

Correspondence to: Professor D. A. McGrouther, Division of Plastic Surgery, University College London, The Rayne Institute, 5 University Street, London WC1E 6JJ, UK. further letter to the same journal by Norris ${ }^{7}$ summarises the physician's view: 'In my extensive experience in managing keloids I have not had a problem differentiating hypertrophic scars from keloids although in some cases it may take a number of months before it is clear'! 'It will not be very long before we will have the laboratory methods to differentiate between the two'.

In this review it is proposed to side-step this insoluble controversy and use the term HK scars to cover the whole spectrum of hypertrophic and/or keloid formation whatever their interrelationship may be.

At the outset, it is important to define terms. A scar is considered clinically to be the visible mark of a wound and histologically it is the resultant fibroblast reaction. Curiously, a wound is much more difficult to define. Depending on the order of magnitude, it may be considered as a breach in continuity of tissue or a cellular disruption. Histologically a key feature would appear to be signs of an inflammatory cellular reaction.

\section{NON-SCARRING WOUNDS}

Not all wounds will inevitably give rise to a scar. Examples are tattoos and venepunctures. Interestingly, a superficial scratch which may trigger a Lewis's triple response and even a prolonged inflammatory reaction will not scar unless it extends to a certain critical depth in the dermis. This is a clinical observation. Let us suppose a rose thorn or similar sharp object is drawn across the surface of the skin; as the thorn first comes in contact with the skin the mark is superficial and becomes progressively deeper. There seems to be a critical point before which the scratch will heal without a visible mark and after which the wound will leave a permanent scar. It is for this reason that animals reared for their hides in the manufacture of such quality items as leather automobile seats must be kept away from barbed wire fences! The same phenomenon is seen with oblique slash injuries which gradually taper at their ends. There appears to be a point where scarring will commence. This same phenomenon is well known to plastic surgeons cutting a split skin graft. A thin graft will heal with no residual scarring, a slightly deeper graft will result in an alteration in pigmentation and a still

Eye (1994) 8, 200-203 C 1994 Royal College of Ophthalmologists 
deeper graft will scar and may stimulate an HK response. The precise depths at which these changes occur are not known and almost certainly vary from one skin area to another. In searching for an explanation it is possible to hypothesise that wounding the dermis to a certain critical depth alters its mechanical integrity allowing the wound to gape and producing a mechanical or physical signal which is transduced as a cellular reaction. Alternatively, certain chemical influences might be invoked through damaging the dermis at a certain depth. For example, such damage may excite endothelial or neural mechanisms.

\section{SCAR MORPHOLOGY}

It is now appropriate to consider the spectrum of clinical appearances of scar tissue. Scars, whether linear as following surgery, or affecting an area as after burns, may acquire a variety of different appearances. All are raised and red at the outset due to oedema and vasodilatation of the margins and of the scar tissue itself. This predictable appearance varies greatly in extent and duration but will, with few exceptions, eventually lead to a scar which is whiter and flatter. Sometimes a scar may stay red almost indefinitely (without being raised), particularly in a patient with a reddish skin complexion (a clinical observation impossible to quantitate).

A variety of other events may ensue. The scar may widen or stretch. This is very likely in certain sites; for example, the back. Alternatively, scar tissue may contract and result in disfigurement and deformity. There is often confusion between the various events in a scar. Stretching or widening and contraction are mutually exclusive although one or other may predominate at different times in the genesis of a scar. The essential feature of an HK scar is that it becomes raised. It is also red (vascular) and may undergo delayed maturation (it may fail to progress to a flat pale scar in the usual time). Where a scar widens (stretches) significantly and develops an HK behaviour it will have the most dramatic appearances. The triad of widening, HK appearance and contraction will determine the overall clinical appearance.

If we now focus on HK scars alone, an explanation of appearances can be developed which explains different types of extension and elevation. Scar width may be explained more by edge retraction rather than by any supposed expanding nature of the lesion. This would be a feasible explanation for such scars as presternal keloid which seem gradually to extend over a period of time. Retraction is, however, a less feasible explanation for a keloid scar which seems to encroach on an adjacent anatomical territory. A study by Meyer and $\mathrm{McGrouther}^{8}$ showed that on making punch wounds down the midline of a cadaver, the skin over the upper sternum retracted little, while the skin over the lower sternum appeared to retract due to inherent elasticity in both vertical and horizontal dimensions; it has been observed following cardiac surgery that this is a frequent area for scar hypertrophy. In the upper epigastrium the punch holes resulted mostly in a transverse gaping of the punch hole; in this area surgical scars have a greater tendency to stretch horizontally. These findings would suggest that in some way HK formation may occur where the scar is subject to multi-axial tension forces.

The vertical growth phase of a scar (thickness) may depend on growth along the lines of least resistance such that in some circumstances the scar may tend to become polypoidal, rising above the surface, whereas in others it may extend into loose subcutaneous tissue. The difficulty in interpreting deep extension in a pathological sense is that it is difficult to know how much deep trauma there has been in a wound and whether, therefore, the HK tissue has developed in injured tissue or extended into uninjured tissue. The understanding of extension is thus very subjective. If it does occur it is limited and it does not amount to a neoplastic invasion.

\section{CLINICAL PHENOMENOLOGY}

There are a number of repeatable clinical observations which relate to scars and other fibrotic conditions and these hold clues to the understanding of HK scarring.

1. HK scars are the predictable (normal) mode of healing in certain genetic phenotypes as shown by tribal markings. Related to this observation is the fact that diseases with a fibrotic component have different incidences in different racial groupings. Dupuytren's disease, for example, is common in northern Europe but almost unknown in Africa and generally seems to have a negative correlation with HK scarring. Cirrhosis of the liver and renal and vascular diseases with a fibroblastic component have widely varying incidences in different population groups.

2. A scar may be only partly HK, particularly where different branches of the scar have different orientations, giving rise to speculation about the role of skin tension. The classic work of Karl Langer, translated by Gibson, ${ }^{9}$ commented on a number of mechanical properties of the skin including skin retraction after wounding, but little is known about the dynamics of skin tension in a living, breathing and moving subject.

3. The age of injury seems important, as ear piercing in early infancy is much less likely to give an HK scar than if performed in the teenage years, although no true population studies on this bizarre and ubiquitous ritual are known. Also, the umbilical scar at birth does not form an HK scar even in those with a strong genetic disposition.

4. Body site is critical. HK scars 'never' develop in the palm (occasionally there is some scar thickening) and HK scars are rare over the extensor surface of joints. Common sites are the presternal region, shoulders and ear lobes. There may be a considerable variety of explanations for these findings and different mechanisms, mechanical or cellular, may apply.

5. When excised and skin grafted, the HK scarring develops at the margins of the graft rather than beneath the skin graft itself. There may be thickening of the graft bed but it will not become as lumpy and raised as the marginal scar.

6. Treatments have a variable effect but there is some 
evidence for HK scar improvement under the action of pressure, steroid injection or radiotherapy. Ambrose Parey, was the first to describe pressure to deforming scars and contractures in $1678 .{ }^{4}$

\section{HK TISSUE}

Most aetiological studies have centred on the tissue, the cells or the molecules within the scar, although some suggestion of a generalised process has been made in the form of an abnormal immune response. ${ }^{10}$

The cellular components of HK tissue are fibroblasts, macrophages, endothelial cells and neural fibres with keratinocytes in the overlying epithelium. Their individual roles will now be considered.

In relation to fibroblasts, the main thrust of research has been to try to demonstrate whether the fibroblasts of $\mathrm{HK}$ scarring represent a different cell population from normal wound healing. Myles et al. ${ }^{11}$ demonstrated some differences in the fibroblast population in that keloid fibroblasts were refractory to inhibition of DNA synthesis by phorbol esters. In addition keloid fibroblasts had a reduced sensitivity to prostaglandin $\mathrm{E}_{2}$ compared with normal fibroblasts. Their findings suggested that altered expression of protein kinase $\mathrm{C}$ isozymes or another molecule that binds phorbol esters may play a role in abnormal growth regulation of keloid cells. Sit et al. ${ }^{12}$ noted differential oxygen sensitivity in glucose-6-phosphate dehydrogenase (G6PDH) activities; under oxygen saturation conditions keloid G6PDH activities were greater than in normal skin. Lee et $a l .{ }^{13}$ showed high levels of type I and type III procollagen mRNAs in keloid tissue and suggested that a subpopulation of cells was responsible for the increased collagen.

A central role for endothelial cells has been suggested by Sollberg et al. ${ }^{14}$ who noted pro alpha-1 collagen mRNAs in microvascular endothelial cells. A possible neural mechanism has been demonstrated by Parkhouse et $a l .^{15}$ who reported increased neuropeptides in hypertrophic painful scars.

Various abnormalities in extracellular matrix have been recorded. Fibronectin gene transcription is enhanced in normal wound healing ${ }^{16}$ and fibronectin is overproduced by keloid fibroblasts (fourfold). ${ }^{17}$ Shetlar et al.${ }^{18}$ implanted HK fibroblasts into athymic nude mice to study glycosaminoglycan production. Garg et al. ${ }^{19}$ described proteoglycan fractions in post-burn keloid scars and Messadi and Bertolami $^{20}$ noted that an HA receptor CD44 (cell adhesion molecule and putative receptor for hyaluronan) was increased in hypertrophic scar fibroblasts.

Collagen has received less attention in recent years although a study by Di Cesare et $a l^{21}$ reported increased type III collagen, and Low and Moy $^{22}$ speculated on the possibility of targeting pharmacological actions to reduce collagen production.

\section{GROWTH FACTORS}

Not surprisingly there has been considerable activity in the investigation of a variety of growth factors. Tan et al. ${ }^{23}$ reported that fibroblast growth factor (FGF) downregulates excess collagen production by keloid fibroblasts. McCauley et $a .^{24}$ reported altered cytokine production in black patients with keloids. Dustan ${ }^{25}$ discussed growth factor and racial differences in relation to keloids, hypertension and renal diseases. Tan and Peltonen ${ }^{26}$ described a mechanism by which endothelial cell growth factor (ECGF) and heparin regulate collagen gene expression in keloid fibroblasts. Peltonen et al. ${ }^{27}$ reported that the initial step in the development of a fibrotic reaction in keloid involved expression of transforming growth factor beta-1 (TGF $\beta 1$ ) gene by neovascular endothelial cells. Castagnoli et al. ${ }^{28}$ described reduced tumour necrosis factor alpha (TNF $\alpha$ ) in hypertrophic scars and Parkhouse et al. ${ }^{15}$ described an increase in neuropeptides in scar tissue. Shah et $a{ }^{29}{ }^{2}$ found that the use of neutralising antibodies to TGF $\beta 1$ and TGF $\beta 2$ produced an improved quality of wound healing. The possibility of growth factor treatment with interferon gamma has been described by Granstein $e t$ $a l .{ }^{30}$ and Larrabee et al., ${ }^{31}$ but therapeutic studies are currently at an early stage.

\section{MANAGEMENT}

Assessment of progress has been hampered by a lack of objective measurement. Potentially valuable clinical techniques are observations by Hambleton et al. ${ }^{32}$ who measured scar thickness by ultrasound and by Ehrlich and Kelly ${ }^{33}$ who noted increased blood flow on laser Doppler blood flow studies. In relation to treatment, Sproat et al. ${ }^{34}$ have compared steroid with silicone gel; Sawada and Sone ${ }^{35}$ have described the use of hydration and occlusion; and Lee and Ping ${ }^{36}$ have investigated the possible use of a calcium antagonist drug.

\section{REFERENCES}

1. Alibert JLM. Description des maladies de la peau observées a l'hospital Saint-Louis et exposition des meilleurs méthodes suivés pour leur traitement. Paris: Barrois l'Aine et Fils, 1806.

2. Alibert JLM. Note sur la keloide. J Univ Sci Med 1816;2:207.

3. Alibert JLM. Quelques recherches sur la cheloide en mémoires de la société d'emulation. Paris: Migneret, Crochard et Gabon, 1817.

4. Linares HA, Larson DL, Willis-Galstaun BA. Historical notes on the use of pressure in the treatment of hypertrophic scars or keloids. Burns 1993;19(1):17-21.

5. Rockwell WB, Cohen IK, Ehrlich HP. Keloids and hypertrophic scars: a comprehensive review. Plastic Reconstructive Surg 1989;84:827-37.

6. Brody GS. Keloids and hypertrophic scars [letter]. Plastic Reconstructive Surg 1990;86:804.

7. Norris JE. Hypertrophic scar and keloid [letter]. Plastic Reconstructive Surg 1991;88:372-3.

8. Meyer M, McGrouther DA. A study relating wound tension to scar morphology in the pre-sternal scar using Langer's technique. Br J Plastic Surg 1991;44:291-4.

9. Langer K. On the anatomy and physiology of the skin. Translation by T Gibson. Br J Plastic Surg 1978;31:3-8, 93106, 185-99, 273-8.

10. Placik OJ, Lewis VL. Immunologic associations of keloids. Surg Gynecol Obstet 1992;175:185-93.

11. Myles ME, Russell JD, Trupin JS, Smith JC, Russell SB. 
Keloid fibroblasts are refractory to inhibition of DNA synthesis by phorbol esters: altered response is accompanied by reduced sensitivity to prostaglandin $\mathrm{E}_{2}$ and altered downregulation of phorbol ester binding sites. J Biol Chem 1992;267:9014-20.

12. Sit KH, Lau YK, Aw SE. Differential oxygen sensitivities in G6PDH activities of cultured keloid and normal skin dermis single cells. J Dermatol 1991;18:572-9.

13. Lee KS, Song JY, Suh MH. Collagen mRNA expression detected by in situ hybridisation in keloid tissue. J Dermatol Sci 1991;2:316-23.

14. Sollberg S, Peltonen J, Uitto J. Combined use of in situ hybridisation and unlabelled antibody peroxidase anti-peroxidase methods: simultaneous detection of type I procollagen mRNAs and factor VIII-related antigen epitopes in keloid tissue. Lab Invest 1991;64:125-9.

15. Parkhouse N, Crowe R, McGrouther DA, Burnstock G. Painful hypertrophic scarring and neuropeptides [letter]. Lancet 1992;340:1410.

16. Oliver N, Babu M, Diegelmann R. Fibronectin gene transcription is enhanced in abnormal wound healing. J Invest Dermatol 1992;99:579-86.

17. Babu M, Diegelmann R, Oliver N. Fibronectin is overproduced by keloid fibroblasts during abnormal wound healing. Mol Cell Biol 1989;9:1642-50.

18. Shetlar MR, Shetlar CL, Kischer CW, Pindur J. Implants of keloid and hypertrophic scars into the athymic nude mouse: changes in the glycosaminoglycans of the implants. Connect Tissue Res 1991;26:23-6.

19. Garg HG, Lippay EW, Burd DA, Neame PJ. Purification and characterisation of iduronic acid-rich and glucuronic acidrich proteoglycans implicated in human post-burn keloid scar. Carbohydrate Res 1990;207:295-305.

20. Messadi DV, Bertolami CN. CD44 and hyaluronan expression in human cutaneous scar fibroblasts. Am J Pathol 1993;142:1041-9.

21. DiCesare PE, Cheung DT, Perelman N, Libaw E, Peng L, Nimni ME. Alteration of collagen composition and crosslinking in keloid tissues. Matrix 1990;10:172-8.

22. Low SQ, Moy RL. Scar wars strategies: target collagen. J Dermatol Surg Oncol 1992;18:981-6.

23. Tan EM, Rouda S, Greenbaum SS, Moore JH Jr, Fox JW, Sollberg S. Acidic and basic fibroblast growth factors downregulate collagen gene expression in keloid fibroblasts. Am J Pathol 1993;142:463-70.
24. McCauley RL, Chopra V, Li YY, Herndon DN, Robson MC. Altered cytokine production in black patients with keloids. $\mathrm{J}$ Clin Immunol 1992;12:300-8.

25. Dustan HP. Growth factors and racial differences in severity of hypertension and renal diseases. Lancet 1992; 339:1339-40.

26. Tan EM, Peltonen J. Endothelial cell growth factor and heparin regulate collagen gene expression in keloid fibroblasts. Biochem J 1991;278:863-9.

27. Peltonen J, Hsiao LL, Jaakkola S, Sollberg S, Aumailley M, Timpl R, Chu ML, Uitto J. Activation of collagen gene expression in keloids: colocalisation of type I and VI collagen and transforming growth factor-betal mRNA. J Invest Dermatol 1991;97:240-8.

28. Castagnoli C, Stella M, Berthod C, Magliacani G, Richiardi PM. TNF production and hypertrophic scarring. Cell Immunol 1993; 147:51-63.

29. Shah M, Foreman DM, Ferguson MWJ. Control of scarring in adult wounds by neutralising antibody to transforming growth factor $\beta$. Lancet 1993;339:213-4.

30. $r$. Istein RD, Flotte IJ, Amento EP. Interferons and collagen production. J Invest Dermatol 1990;95 (Suppl 6):758-808.

31. Larrabee WF Jr, East CA, Jaffe HS, Stephenson C, Peterson KE. Intralesional interferon gamma treatment for keloids and hypertrophic scars. Arch Otolaryngol Head Neck Surg 1990;116:1159-62.

32. Hambleton J, Shakespeare PG, Pratt BJ. The progress of hypertrophic scars monitored by ultrasound measurements of thickness. Burns 1992;18:301-7.

33. Ehrlich HP, Kelley SF. Hypertrophic scar: an interruption in the remodeling of repair: a laser Doppler blood flow study. Plastic Reconstructive Surg 1992;90:993-8.

34. Sproat JE, Dalcin A, Weitauer N, Roberts RS. Hypertrophic sternal scars: silicone gel sheet versus Kenalog injection treatment. Plastic Reconstructive Surg 1992;90:988-92.

35. Sawada Y, Sone K. Hydration and occlusion treatment for hypertrophic scars and keloids. $\mathrm{Br} \mathrm{J}$ Plastic Surg 1992;45:599-603.

36. Lee RC, Ping JA. Calcium antagonists retard extracellular matrix production in connective tissue equivalent. J Surg Res 1990;49:463-6. 